Effect of Traveler's Nationality on Daily Travel Time Expenditure Using Zero-Inflated Negative Binomial Regression Models Results from Belgian National Household Travel Survey

Peer-reviewed author version

Eftekhar, Hamed; CREEMERS, Lieve \& COOLS, Mario (2016) Effect of Traveler's Nationality on Daily Travel Time Expenditure Using Zero-Inflated Negative Binomial Regression Models Results from Belgian National Household Travel Survey. In: TRANSPORTATION RESEARCH RECORD,(2565), p. 65-77.

DOI: $10.3141 / 2565-08$

Handle: http://hdl.handle.net/1942/24004 


\section{ASSESSING THE EFFECT OF TRAVELER'S NATIONALITY ON DAILY TRAVEL TIME EXPENDITURE USING ZERO-INFLATED NEGATIVE BINOMIAL REGRESSION MODELS: RESULTS FROM THE BELGIAN NATIONAL HOUSEHOLD TRAVEL SURVEY}

\section{Hamed Eftekhar}

University of Liège, ARGENCO, Local Environment Management \& Analysis (LEMA)

Quartier Polytech 1, Allée de la Découverte 9, BE-4000 Liège, Belgium

Tel: +3243669869

Fax: +3243662909

Email: H.Eftekhar@ulg.ac.be

\section{Lieve Creemers}

Hasselt University, Transportation Research Institute (IMOB)

Wetenschapspark 5 bus 6, BE-3590 Diepenbeek, Belgium

Tel: +32 11269134

Email: lieve.creemers@uhasselt.be

\section{Mario Cools, Corresponding Author}

University of Liège, ARGENCO, Local Environment Management \& Analysis (LEMA)

Quartier Polytech 1, Allée de la Découverte 9, BE-4000 Liège, Belgium

Tel: +324366 4813

Fax: +324366 2909

Email: mario.cools@ulg.ac.be

Word count: 4,591 words text +10 tables/figures x 250 words (each) +31 references $=7,091$ words

Submission Date: November 15, 2015 


\section{ABSTRACT}

2 In this paper, the effect of traveler's nationality on daily travel time expenditure is assessed using data 3 stemming from the 2010 Belgian national household travel survey. In particular, different (zero-inflated) negative binomial models were estimated to isolate the effect of nationality, after controlling for other contributing factors such as socio-demographics, residential characteristics, transport options and temporal characteristics. The results indicate that, even if one controls for a series of other influencing factors, nationality plays a significant role in differences in travel time expenditure. This finding is especially relevant in the development of policy packages that are targeted to tackle social inequalities. From a methodological perspective, different methodological options, i.e. two weighting schemes and two bootstrap solutions, were presented to provide sufficient support for the conclusions. In order to generalize the results in further studies, an oversampling of travelers with a different nationality is strongly recommended. Future research should focus more on the underlying psychological constructs of why ethnic and cultural differences persist, even if one accounts for other determinants.

Keywords: nationality, travel time expenditure, travel time budget, zero-inflated negative binomial 16 regression, bootstrapping 
2

3

4

\section{INTRODUCTION}

Over the past decades, in many western countries the proportion of immigrants has increased considerably and this tendency is expected to continue in the foreseeable future (1-2). As a result, populations become more ethnically and culturally diverse. This increased diversity in turn affects the socio-economic and demographic composition of the population and consequently alters travel behaviour patterns. Hence, a deeper understanding of the underlying travel behaviour could help to find suitable policies that addresses environmental and ethnic justice concerns and thus meets the travel needs of all population groups (3-6). To enhance the success of such policies, empirical research on the relationship between ethnicity and other factors, which directly and indirectly influence travel behaviour, is critical $(5,7)$. This relationship can be investigated by examining the ethnic variation of people's travel time expenditures and the factors contributing to such expenditures $(8)$. The contribution of ethnic diversity in altering travel behaviour within a population is especially prominent from a social exclusion point of view that calls for the inclusion of time use analyses (9).

Literature indicates the relevance of ethnic differences on various levels of the trip-making decision process. Concerning short-term decisions, ethnicity significantly influences mode choice and destination choice (10-13). In particular, Bora et al. (13) concluded that areas populated by persons of a particular nationality are visited more frequently by other members of that community. Further evidence of the relationship between destination choice and ethnicity is provided by Silm and Ahas (14), who found that ethnicity has a significant impact on the activity spaces of out-of-home non-work activities. With regard to long-term decisions, literature points out the significant influence of ethnicity on car ownership, residential location and home ownership $(5,7,11,15)$.

Regarding daily travel time expenditure, Volosin et al. (8) underline that it is a key measure of travel demand and that a thorough comprehension of contributing factors can help in increasing the performance of travel demand forecasts, for instance by balancing mode choice preference and travel demand to achieve an acceptable level of service. Moreover, they expanded the notion of a travel time frontier developed by Banerjee et al. (16) and concluded that the frontier values, as well as the ratio of the travel time expenditure to these frontier values differ considerably across socio-demographic groups. With respect to the factors explaining differences in daily travel time expenditure a variety of socio-demographic variables, residential characteristics, transport options, modal choice habits and journey characteristics play a significant role (17-25).

The role of ethnic variety on travel behaviour and the importance of daily travel time expenditure in transportation planning, as described above, underline the need for investigating the effect of ethnic differences on daily travel time expenditure within the Belgian context. The research particularly focuses on whether the total daily travel time expenditure (i.e. the travel time spent on all trips realized during the day of reporting, irrespective of the trip motive) as well as daily travel time expenditure for the most common trip motives varies by nationality.

The remainder of the text is structured as follows. First, the data that is used to assess the differences by nationality is described, and some basic descriptive statistics are provided. Then, the methodology is detailed, followed by a discussion of the results. Finally, the main conclusions are formulated and some avenues for further research are indicated. 


\section{DATA}

In order to assess the effect of nationality on daily travel time expenditure, data stemming from the 2010 Belgian National Household Travel Survey (abbreviated as BELDAM (26)) is analysed. For each individual, the daily travel time expenditure was defined as the sum of the durations of all trips performed during the day of reporting. Note that the daily travel time expenditure was defined as zero for the respondents who indicated that they did not make any trip during the day of reporting.

Although the individuals with a zero travel time are interesting from the perspective of studying immobility (27), they were disregarded from further analysis because the day of reporting was not recorded for these individuals within the BELDAM survey. After all, in the questionnaire design of the BELDAM survey, information with respect to temporal information (including the date) was recorded in the trip diary, which was returned empty for individuals that did not produce any trips. However, information about the day of reporting is essential given the large importance attributed to daily travel time expenditure, in the context of day-of-week and holiday effects (19).

With respect to factors accounting for differences in daily travel time expenditure, it should be highlighted that information about the main factor of interest, i.e. nationality, was collected in the person questionnaire of the BELDAM survey. Given the fact that the BELDAM survey uses a random sample from the population residing in Belgium, the relative share of respondents with a nationality different from the Belgian nationality is relatively low. Therefore, the analysis focuses only on the nationalities for which at least 30 individuals were surveyed. In particular, data from travellers with the following six nationalities were considered, with the number of unweighted observations reported between brackets: Belgian (7399), French (153), Italian (135), Dutch (51), Spanish (37), Moroccan (36). To account for the imbalance in the number of observations per nationality, a dedicated methodology has been adopted (see Section 4), to make sure that the relative weight of each group in the final analysis is equal, ensuring the optimal efficiency in the comparison of the different nationalities.

Besides nationality, a series of other factors that have been indicated as contributing factors of travel time expenditure, are incorporated in the data. These additional factors could be broadly categorized into socio-demographics, residential characteristics, transport options and mode use frequencies, and temporal characteristics. Remind that these factors were highlighted as significant in the introduction section. With respect to the socio-demographical factors, the age, gender, obtained educational level and professional activity of the respondents were considered for the analysis as well as the net monthly household income, the household size and whether the respondent had a partner/companion and/or children. With regard to the residential characteristics, the urbanization degree of the residence, dwelling type, and ownership were taken into account. Concerning the transport options, the respondent's possession of a season ticket for public transport and driver's license were considered, as well as the bike and car possession at the household level. Furthermore, it was explicitly considered if the respondent's mobility was restricted due to impairments. In addition, the frequency (defined as at least four days a week) of walking, biking, car use (either as driver or passenger) and public transit were assessed. Finally, in terms of temporal characteristics, the effect of weekend days and school holidays was taken into account, as well as the travel time expenditure spent on the remaining trip motives (referred to as "travel time expenditure: other"). The latter was defined as the difference between the total travel time expenditure and the travel time expenditure on trips for a given motive. 


\section{DESCRIPTIVE ANALYSIS}

Before elaborating on the methodology in Section 4, an overview of the basic descriptive statistics of the travel time expenditures per nationality and per trip motive is given in Table 1 . These expenditures only correspond to respondents that made at least one trip during the day of reporting, as was explained in the previous section. The share of respondents that did not made any trip during the day of reporting, defined as immobility, is also presented in Table 1. From this table we can observe that large differences exist between the different nationalities, especially in the context of total travel time expenditure (i.e. the travel time spent on all trips realized during the day of reporting, irrespective of the trip motive) and visits. The most striking difference is especially the considerable higher travel time expenditure on visit trips by travellers with a French nationality, who spend even more than double the other nationalities investigated.

TABLE 1 Daily Travel Expenditure (in Minutes) and Immobility (in \%) Per Nationality

\begin{tabular}{|l|l|r|r|r|r|r|r|}
\hline \multirow{2}{*}{ Expenditure } & Parameter & $\begin{array}{r}\text { Belgian } \\
\text { Total }\end{array}$ & $\begin{array}{r}\text { Spanish } \\
(\mathbf{E S})\end{array}$ & $\begin{array}{r}\text { French } \\
(\mathbf{F R})\end{array}$ & $\begin{array}{r}\text { Italian } \\
(\mathbf{I T})\end{array}$ & $\begin{array}{r}\text { Moroccan } \\
(\mathbf{M A})\end{array}$ & $\begin{array}{r}\text { Dutch } \\
(\mathbf{N L})\end{array}$ \\
\hline \multirow{2}{*}{ Commuting } & Mean & 80.0 & 75.0 & 100.0 & 67.8 & 82.2 & 99.4 \\
\cline { 2 - 8 } & Std. Dev. & 6.1 & 45.9 & 48.5 & 27.1 & 85.6 & 56.8 \\
\hline \multirow{2}{*}{ Shopping } & Mean & 24.8 & 30.5 & 34.9 & 24.0 & 26.3 & 29.7 \\
\cline { 2 - 8 } & Std. Dev. & 3.1 & 40.0 & 20.3 & 21.8 & 40.2 & 36.8 \\
\hline \multirow{2}{*}{ Leisure } & Mean & 12.0 & 13.8 & 11.8 & 8.6 & 15.7 & 12.7 \\
\cline { 2 - 8 } & Std. Dev. & 3.1 & 27.4 & 13.5 & 9.1 & 33.7 & 19.8 \\
\hline \multirow{2}{*}{ Visits } & Mean & 7.9 & 9.1 & 6.8 & 4.8 & 2.1 & 7.0 \\
\cline { 2 - 8 } & Std. Dev. & 2.5 & 26.8 & 12.9 & 8.5 & 10.2 & 11.2 \\
\hline Immobility & Mean & 8.9 & 4.9 & 20.1 & 5.7 & 7.2 & 6.9 \\
\cline { 2 - 8 } & Std. Dev. & 2.1 & 12.3 & 43.7 & 7.8 & 26.2 & 16.4 \\
\hline
\end{tabular}

Table 2 provides an overview of the descriptive statistics of the remaining explanatory factors considered in the study. For the continuous variables, the correlation with the travel time expenditure is given, whereas for the categorical explanatory variables the mean travel time expenditures are tabulated per category. From this table, one could observe that the different types of explanatory variables, i.e. socio-demographics, residential characteristics, transport options and usage and temporal characteristics all appear to account for at least a part in daily travel time expenditure. Regarding total travel time expenditure, especially education, professional activity and the possession of a season ticket for public transit use exhibit differences. Concerning travel time expenditure on commuting trips, large differences can be detected for professional activity, possession of a season ticket and, and the day of reporting (weekend day or not). With respect to differences in travel time expenditure on shopping trips, especially differences regarding the possession of a driver license and the occurrence of a (school) holiday are appealing. With regard to leisure trips, noticeable higher travel time expenditures can be found among travellers during weekends and among those who are frequently using the bicycle as transportation mode. This is in line with the fact that people will choose bikes or car for weekend social trips for having more freedom in their mobility schedule. Finally, concerning visit trips, the considerable difference between school holidays and regular days draws the attention. 
1 TABLE 2 Descriptive Statistics Travel Time Expenditure and Explanatory Variables

\begin{tabular}{|c|c|c|c|c|c|}
\hline Parameter & Total & Commuting & Shopping & Leisure & Visits \\
\hline \multicolumn{6}{|c|}{ Continuous explanatory variables (Pearson correlation) } \\
\hline Age & 0.027 & -0.157 & 0.174 & -0.044 & 0.063 \\
\hline Household size & -0.066 & 0.038 & -0.110 & -0.009 & -0.015 \\
\hline Travel time expenditure other & N/A & -0.291 & -0.076 & -0.068 & -0.129 \\
\hline \multicolumn{6}{|c|}{ Categorical explanatory variables (Average Expenditure in Minutes per category) } \\
\hline \multicolumn{6}{|c|}{ Socio-Demographics } \\
\hline Gender: Female & 84.5 & 26.3 & 14.2 & 6.2 & 9.9 \\
\hline Gender: Male & 83.7 & 30.4 & 10.7 & 6.3 & 8.0 \\
\hline Higher Education: Yes & 100.1 & 33.9 & 15.9 & 6.9 & 8.9 \\
\hline Higher Education: No & 72.3 & 24.3 & 9.9 & 5.9 & 9.0 \\
\hline Professional Activity: Yes & 95.1 & 39.9 & 10.8 & 4.5 & 5.9 \\
\hline Professional Activity: No & 71.8 & 15.6 & 14.2 & 8.3 & 12.3 \\
\hline Net monthly household income: $0-1499 €$ & 79.1 & 19.6 & 12.5 & 7.8 & 9.4 \\
\hline Net monthly household income: $1500-3999 €$ & 88.3 & 29.4 & 14.2 & 6.4 & 12.0 \\
\hline Net monthly household income: $\geq 4000 €$ & 88.2 & 35.3 & 8.9 & 5.8 & 4.8 \\
\hline Net monthly household income: undeclared & 64.7 & 30.4 & 11.4 & 2.5 & 1.2 \\
\hline Companion: Yes & 88.9 & 28.6 & 15.0 & 4.9 & 9.2 \\
\hline Companion: No & 77.7 & 28.0 & 9.1 & 8.1 & 8.6 \\
\hline Having child(ren): Yes & 87.2 & 28.9 & 11.1 & 5.8 & 6.5 \\
\hline Having child(ren): No & 82.7 & 28.1 & 13.0 & 6.5 & 10.0 \\
\hline \multicolumn{6}{|l|}{ Residential Characteristics } \\
\hline Urbanization residence: Urban & 81.5 & 28.0 & 12.4 & 6.1 & 9.5 \\
\hline Urbanization residence: Sub-Urban. Rural & 90.0 & 29.3 & 12.5 & 6.7 & 7.7 \\
\hline HH dwelling ownership: Yes & 82.3 & 27.2 & 12.1 & 5.0 & 10.8 \\
\hline HH dwelling ownership: No & 86.9 & 30.3 & 13.1 & 8.5 & 5.8 \\
\hline HH dwelling is detached house: Yes & 89.7 & 24.9 & 14.6 & 6.6 & 7.4 \\
\hline HH dwelling is detached house: No & 82.6 & 29.3 & 11.9 & 6.2 & 9.3 \\
\hline \multicolumn{6}{|l|}{ Transport Options and Mode Use Frequencies } \\
\hline Season ticket for public transport: Yes & 103.6 & 39.3 & 13.8 & 8.7 & 11.3 \\
\hline Season ticket for public transport: No & 76.5 & 24.2 & 11.9 & 5.4 & 8.0 \\
\hline Car driving license: Yes & 91.7 & 29.2 & 14.3 & 5.6 & 9.7 \\
\hline Car driving license: No & 63.1 & 26.1 & 7.3 & 8.2 & 6.9 \\
\hline Mobility restraints: Yes & 59.7 & 23.1 & 10.0 & 6.1 & 9.2 \\
\hline Mobility restraints: No & 88.9 & 29.4 & 12.9 & 6.3 & 8.9 \\
\hline Bike possession: Yes & 92.1 & 31.5 & 12.2 & 6.9 & 9.3 \\
\hline Bike possession: No & 66.2 & 21.3 & 13.0 & 4.9 & 8.3 \\
\hline Car possession: Yes & 84.1 & 28.3 & 13.2 & 5.6 & 8.8 \\
\hline Car possession: No & 83.7 & 28.7 & 9.4 & 9.1 & 9.4 \\
\hline Frequent walking: Yes & 86.9 & 26.7 & 13.5 & 7.0 & 9.7 \\
\hline Frequent walking: No & 74.0 & 34.3 & 8.5 & 3.9 & 6.4 \\
\hline Frequent cycling: Yes & 90.3 & 24.5 & 12.8 & 14.2 & 9.9 \\
\hline Frequent cycling: No & 82.4 & 29.4 & 12.3 & 4.2 & 8.7 \\
\hline Frequent public transit use: Yes & 93.7 & 37.0 & 11.9 & 7.5 & 6.4 \\
\hline Frequent public transit use: No & 76.9 & 22.0 & 12.8 & 5.4 & 10.8 \\
\hline Frequent car use: Yes & 86.3 & 27.0 & 13.3 & 5.0 & 10.0 \\
\hline Frequent car use: No & 76.3 & 33.0 & 9.4 & 10.7 & 5.3 \\
\hline \multicolumn{6}{|l|}{ Temporal Characteristics } \\
\hline Weekend day: Yes & 75.1 & 9.1 & 16.5 & 12.1 & 11.0 \\
\hline Weekend day: No & 87.1 & 35.0 & 11.0 & 4.3 & 8.2 \\
\hline School holiday: Yes & 80.5 & 29.9 & 7.9 & 3.3 & 17.1 \\
\hline School holiday: No & 84.7 & 28.1 & 13.3 & 6.8 & 7.4 \\
\hline
\end{tabular}




\section{METHODOLOGY}

\subsection{Negative Binomial Regression}

To investigate the effect of contributing factors on the variability of daily travel time expenditure, and to assess the effect of traveler's nationality in particular, five (zero-inflated) negative binomial models were fitted. From Figure 1, we can observe that for the motive specific travel time expenditures (i.e. time spent travelling for respectively commuting, shopping, leisure and visit trips), a higher number of zeroes is present, as one would normally expect from count data. The inflation of zeroes indicates that during the day of reporting, the traveler did not realize a trip for that particular activity. Note, however, that in the analyses only respondents who indicated that they realized at least one trip during the day or reporting (i.e. mobile respondents) were included. Consequently, for the total travel time expenditure considering all trips together, no zero-values are observed.
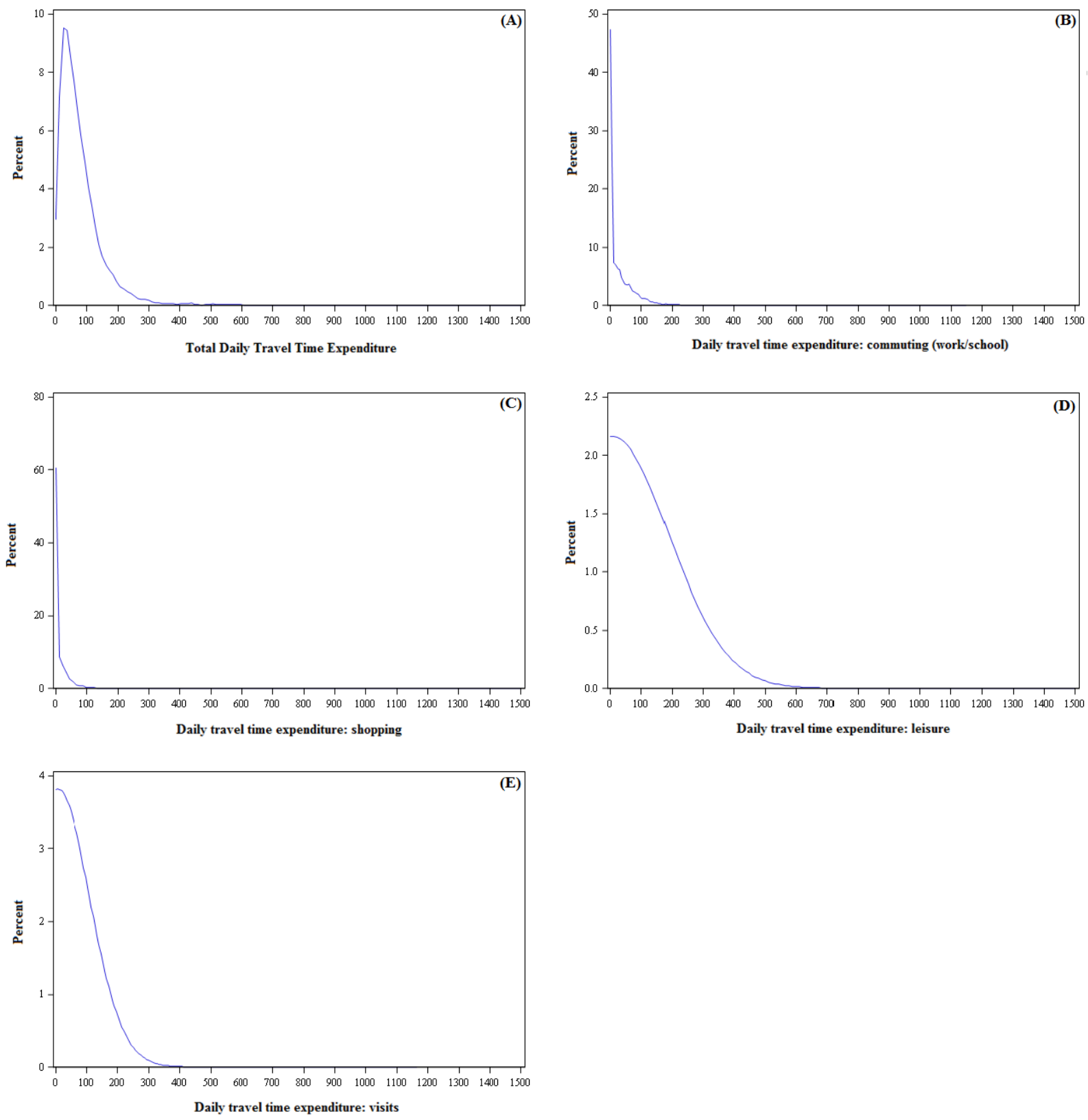
Mathematically, the probability distribution $f(y)$ and $\log$-likelihood function $L$ of the negative binomial model are respectively represented by equations 1 and 2 , which are parametrized in function of the mean $\mu$, and the negative binomial dispersion parameter $k(28-29)$. In this study, the negative binomial model is applied to the total daily travel time expenditure and thus $y$ represents this expenditure. Besides, the mean $\mu$ is calculated by a linear combination of the explanatory variables (presented in Tables 1 and 2).

$f(y)=\frac{\Gamma(y+1 / k)}{\Gamma(y+1) \Gamma(1 / k)} \frac{(k \mu)^{y}}{(1+k \mu)^{y+1 / k}}$ for $y=0,1,2, \ldots$

$L=\sum_{i} l_{i}=\sum_{i}\left[y_{i} \ln \left(\frac{k \mu}{w_{i}}\right)-\left(y_{i}+w_{i} / k\right) \ln \left(1+\frac{k \mu}{w_{i}}\right)+\ln \left(\frac{\Gamma\left(y_{i}+w_{i} / k\right)}{\Gamma\left(w_{i} / k\right)}\right)\right]$

The probability distribution and log-likelihood function of the zero-inflated negative binomial are given by equations 3 and 4, where $\omega$ represents the zero-inflation probability and $\lambda$ represents the mean (29-30). In this study, the zero-inflated negative binomial models are estimated for the four motive-specific travel time expenditure models, and correspondingly $y$ represents the expenditure for a particular trip motive. Analogous to the negative binomial model, $\omega$ and $\lambda$ are calculated by a linear combination of the explanatory variables.

$f(y)= \begin{cases}\omega+(1-\omega)(1+k \lambda)^{-1 / k} & \text { for } y=0 \\ (1-\omega) \frac{\Gamma(y+1 / k)}{\Gamma(y+1) \Gamma(1 / k)} \frac{(k \lambda)^{y}}{(1+k \lambda)^{y+1 / k}} & \text { for } y=1,2, \ldots\end{cases}$

$$
L=\sum_{i} l_{i}=\sum_{i}\left\{\begin{array}{l}
\ln \left[\omega_{i}+\left(1-\omega_{i}\right)\left(1+\frac{k \lambda}{w_{i}}\right)^{-w_{i} / k}\right] \\
\ln \left(1-\omega_{i}\right)+y_{i} \ln \left(\frac{k \lambda}{w_{i}}\right) \\
-\left(y_{i}+w_{i} / k\right) \ln \left(1+\frac{k \lambda}{w_{i}}\right) \\
+\ln \left(\frac{\Gamma\left(y_{i}+w_{i} / k\right)}{\Gamma\left(y_{i}+1\right) \Gamma\left(w_{i} / k\right)}\right)
\end{array}\right] \quad y_{i}>0
$$

Note that in the above equations for the log-likelihood, also the observation weight $w_{i}$ is included. As noted in the data description, two sets of weights will be used in the analysis. The first (conservative) set makes sure that the weighted number of observations per nationality is equal to the smallest group size (i.e. 36 observations), whereas the second (progressive) weighting scheme makes sure that the weighted number of observations per nationality is equal and that the (weighted) total number of observations equals the (unweighted) total number of observations used in the analysis (the number of data points). Using this definition, the progressive weights are a linear function of the conservative weights. As a consequence, the differences between the weighting schemes is translated into a linear transformation of the variance of all the variables, and consequently fully captured by the dispersion parameter $\mathrm{k}$ in the (zero-inflated) negative binomial models. As a consequence, with exception of the dispersion parameter, models with conservative weighting will yield the same parameter estimates and standard errors as with progressive weighting.

The models are developed in backward manner, keeping variables significant at the $5 \%$ level of significance in the model. All non-significant variables, with exception of the main variable under study, 
1 i.e. nationality, are omitted from the final model. All explanatory variables in the models are continuous or 2 dummy variables, thus the overall significance of these variables can be assessed by interpreting the 3 corresponding p-values of the Wald chi-square tests. The only exception is the effect of nationality, where 4 the six nationalities were represented by five dummy variables, with the Belgian nationality as the reference 5 category. Since reference coding was used, the overall level of significance is assessed using a likelihood 6 ratio test comparing the final model with the model excluding the five dummy variables.

\subsection{Bootstrapping}

In addition to the weighting procedure that ensures that each investigated nationality has the same weight in the final analysis, a second approach, i.e. bootstrapping, is adopted to verify and validate the results obtained from both weighting approaches. The basic idea behind bootstrapping is that inferences about a population from a sample (in this study the BELDAM sample) can be modelled by resampling the data and by making inferences on these bootstrap samples. The most important advantages of bootstrapping are: $(i)$ the techniques fewer assumptions (e.g. with respect to the data distribution(s) or sample sizes), (ii) greater accuracy in comparison to many classical methods, and (iii) promote understanding (conceptual analogies to theoretical concepts discussed in classical methods) (31). The bootstrapping procedure followed is presented in Figure 2. Similar to the weighting procedure, both a conservative and progressive approach of the bootstrapping process is considered. 


\section{Step 1: Determine the sample size per stratum.}

To ensure maximum efficiency of inter-group (inter-stratum), the same number of observations needs to be drawn from each group.

Conservative approach: the sample size per group is defined as the smallest group size in the original sample, i.e. 36 respondents per nationality.

Progressive approach: the sample size per group is defined as the total number of observations in the original sample divided by the number of groups, i.e. 1302 per nationality.

\section{Step 2: Resampling.}

From each group (i.e. nationality), the required number of observations is drawn using simple random sampling with replacement. This sampling selection procedure is repeated 1000 times, so that 1000 different bootstrap samples are obtained.

\section{Step 3: Inference per bootstrap sample.}

For each of the bootstrap samples, the different (zero-inflated) negative binomials are fitting using the variables that were selected following the weighting procedure. Thus, for each explanatory variable in the models a vector of maximum 1000 parameters is obtained. The size of the final vector might be inferior to 1000 in case of estimation problems (e.g. lack of convergence, or semi-definite Hessian covariance matrix).

\section{Step 4: Final inference.}

For each parameter, the final parameter estimate is defined as the median $\mu_{1 / 2}$ of the 1000 parameters, and the standard error $s$ is defined in an analogue way compared to standard normal confidence intervals, using the average distance to the $95 \%$ percentile bounds, and calculated using formula 5. In this formula, $p_{2.5}$ and $p_{97.5}$ represent respectively the lower and upper bounds of the $95 \%$ bootstrapping percentile interval. For each parameter, the null hypothesis that the parameter is equal to zero, can be by defining the chi-square value equal to the squared value of the median $\mu_{1 / 2}$ divided the standard error $s$. This value follows a chisquare distribution with one degree of freedom.

$$
s=\frac{\frac{\left(\mu_{1 / 2}-p_{2.5}\right)}{1.96}+\frac{\left(p_{97.5}-\mu_{1 / 2}\right)}{1.96}}{2}=\frac{p_{97.5}-p_{2.5}}{3.92}
$$

\section{FIGURE 2 Bootstrapping procedure.}




\section{RESULTS AND DISCUSSION}

\subsection{Overall Results}

To get a comprehensive overview of the different results, the directions of the effects are displayed in Table 3. From this table, we can see that for some variables the effect is ambiguous (visualized by the question marks). This is partially due to the fact that in a zero-inflated model a variable might have an increasing effect on the mean parameter, and simultaneously have an increasing effect on the probability of having a zero and thus decreasing the overall value of the estimate.

TABLE 3 Significance and Direction of Effect

\begin{tabular}{|c|c|c|c|c|c|}
\hline Parameter & Total & Commuting & Shopping & Leisure & Visits \\
\hline \multicolumn{6}{|l|}{ Socio-Demographics } \\
\hline Nationality: ES & $-(2)$ & $+(3)$ & $-(3)$ & $-(3)$ & $-(3)$ \\
\hline Nationality: FR & $+(3)$ & $+(3)$ & $+(3)$ & $-(3)$ & $+(3)$ \\
\hline Nationality: IT & $-(3)$ & $+(3)$ & $-(3)$ & 0 & $-(3)$ \\
\hline Nationality: MA & $+(2)$ & 0 & $+(3)$ & $-(3)$ & 0 \\
\hline Nationality: NL & $+(2)$ & 0 & $+(2)$ & $-(3)$ & $+(2)$ \\
\hline Age & $+(3)$ & $?$ & $+(7)$ & $?$ & $+(3)$ \\
\hline Gender: Female & 0 & $-(5)$ & $+(6)$ & $?$ & $+(3)$ \\
\hline Higher Education & $+(3)$ & $+(3)$ & $+(3)$ & $+(6)$ & $?$ \\
\hline Professional Activity & $+(3)$ & $+(4)$ & $-(3)$ & $-(3)$ & $-(3)$ \\
\hline Net monthly HH income: $1500-3999 €$ & $-(1)$ & $+(3)$ & $-(3)$ & $+(2)$ & 0 \\
\hline Net monthly HH income: $>=4000 €$ & $-(3)$ & $-(2)$ & $-(3)$ & $+(2)$ & $-(2)$ \\
\hline Net monthly HH income: undeclared & $-(3)$ & 0 & $-(3)$ & $-(1)$ & $-(3)$ \\
\hline Household size & $-(3)$ & $+(3)$ & $?$ & $-(2)$ & $?$ \\
\hline Companion & $+(2)$ & $?$ & 0 & $+(3)$ & $-(2)$ \\
\hline Having child(ren) & 0 & $-(3)$ & $?$ & $-(2)$ & $-(3)$ \\
\hline \multicolumn{6}{|l|}{ Residential Characteristics } \\
\hline Urbanization residence: Urban & $-(3)$ & $?$ & $-(3)$ & 0 & $?$ \\
\hline HH dwelling ownership & $-(3)$ & $-(3)$ & $-(3)$ & $-(3)$ & $+(3)$ \\
\hline HH dwelling is detached house & $+(3)$ & $+(2)$ & $+(3)$ & $+(3)$ & 0 \\
\hline \multicolumn{6}{|c|}{ Transport Options and Mode Use Frequencies } \\
\hline Season ticket for public transport & $+(3)$ & $+(6)$ & $?$ & $+(6)$ & $+(3)$ \\
\hline Car driving license & $+(3)$ & $+(2)$ & $+(5)$ & $-(3)$ & $+(6)$ \\
\hline Mobility restraints & $-(3)$ & 0 & $-(3)$ & 0 & 0 \\
\hline Bike possession & $+(4)$ & $+(3)$ & $+(3)$ & $?$ & $+(6)$ \\
\hline Car possession & 0 & $?$ & $?$ & $+(3)$ & $-(3)$ \\
\hline Frequent walking & $+(3)$ & $-(3)$ & $+(6)$ & 0 & 0 \\
\hline Frequent cycling & 0 & 0 & $+(2)$ & $+(7)$ & 0 \\
\hline Frequent public transit use & $+(3)$ & $+(6)$ & $+(3)$ & 0 & 0 \\
\hline Frequent car use & $+(2)$ & 0 & 0 & $?$ & $+(3)$ \\
\hline \multicolumn{6}{|l|}{ Temporal Characteristics } \\
\hline Weekend day & $-(2)$ & $-(4)$ & $+(3)$ & $+(6)$ & $+(6)$ \\
\hline School holiday & 0 & $-(4)$ & $+(2)$ & 0 & $+(6)$ \\
\hline Travel time expenditure other & N/A & $-(7)$ & $-(4)$ & $-(3)$ & $-(8)$ \\
\hline
\end{tabular}

0: no effect, -: negative effect, +: positive effect, ?: ambiguous effect, N/A: not applicable

Values between brackets indicate the number of parameters (in the four models) confirming the effect

A second, although less important reason for the ambiguity, is the fact that the four different models (i.e. conservative and progressive weighting, and conservative and progressive bootstrapping) do not always yield the same direction of effects. In this context, it should be noted that non-significance of 
parameters did not contribute to the ambiguity. Take as an example the effect of higher education on total travel time expenditure, which has an increasing effect in three out of the four models, but was not significant in the conservative bootstrapping model. In the latter case, the effect of this parameter is considered to have a positive (increasing) effect on travel time expenditure.

Recall that the model for the total daily travel time expenditure is modeled using a "classical" negative binomial model, whereas the motive specific models were modelled using a zero-inflated negative binomial model. The need to account for the excess in zeros is confirmed by the likelihood ratio tests that compare the likelihood of the zero-inflated models with the alternative without the zero-inflated part. For each of the motive-specific models, the likelihood ratio tests is highly significant (p-value smaller than 0.001 , acknowledging the need for a zero-inflated model, which was also observed from the inspection of the kernel density estimates of the data distributions shown in Figure 1.

With respect to the direction of the effects, one could observe from Table 3 that for the majority of the variables, the direction of the effect highly depends on the motive. This provides evidence of the notion of the travel time frontier (see e.g. 8), indicating that travelers are not willing to surpass a certain threshold in terms of time travelling a day. Further evidence of this effect is provided by the negative effect of travel time spent on other trip motives than the one under study.

\subsection{Total Daily Travel Time Expenditure}

Parameter estimates of the negative binomial model of the total daily travel time expenditure are displayed in Table 4. From this table, one can observe that in general the estimates of the four adopted techniques lie in the same direction, but that the reported standard errors and p-values using conservative bootstrapping are considerable different. The latter is an indication that when the bootstrap samples are too small in size, the power to detect significant differences is too weak.

Regarding nationality, it should be noted that in comparison to Belgians, French have a significantly higher daily travel time expenditure, whereas Italians spend significantly fewer time travelling on a daily basis. The higher travel time expenditure by French can be explained by their longer travel times on commuting, shopping and visit trips. The lower expenditure by Italians can be accounted for by their lower shopping and visit distance, and by a relative higher proportion of professionally inactive persons. Concerning other socio-demographic effects, one could derive that ttravelers with a degree of higher education spend $13.4 \%(=\exp (0.126)-1)$ more time on travelling in comparison to their counterparts.

With respect to residential characteristics, one could depict that people residing in urban areas have a lower daily travel time expenditure. This can be accounted for by the typical larger and denser number of activity opportunities in urban areas. Moreover, people that are owner of their household dwelling spend less time on travelling. This suggests that in comparison to tenants, owners have a better residential location to satisfy their needs for activity participation. In addition, whether the dwelling type is a detached house has an increasing effect on daily travel time expenditure..

Concerning transport options and mode use, all estimates lie exactly in the direction as one would expect: a higher number of transport options have an increasing effect on daily travel time expenditure. Moreover, the more frequently one uses different transport modes, the higher the daily travel time expenditure. People with physical mobility constraints spend less time travelling, which could be a sign of lower level of out-home activity participation.

Finally, with regard to the temporal characteristics, one could note that less time is spent on travelling during weekend days. Notwithstanding, some preoccupation needs to be taken in generalizing these effect, as this effect was only acknowledged by the two weighted models. 
TABLE 4 Maximum Likelihood Parameter Estimates Negative Binomial Regression Model Total Daily Travel

2 Time Expenditure

\begin{tabular}{|c|c|c|c|c|c|c|c|c|c|}
\hline \multirow[b]{2}{*}{ Parameter } & \multicolumn{3}{|c|}{ Weighting } & \multicolumn{3}{|c|}{ Cons. bootstrapping } & \multicolumn{3}{|c|}{ Prog. bootstrapping } \\
\hline & Est. & S.E. & Sign. & Est. & S.E. & Sign. & Est. & S.E. & Sign. \\
\hline Intercept & & 0.046 & $<0.001$ & 3.683 & 0.389 & $<0.001$ & 3.717 & 0.064 & $<0.001$ \\
\hline \multicolumn{10}{|l|}{ Socio-demographics } \\
\hline Nationality: ES & -0.057 & 0.027 & 0.036 & 0.016 & 0.212 & 0.941 & -0.044 & 0.036 & 0.219 \\
\hline Nationality: FR & 0.185 & 0.020 & $<0.001$ & 0.202 & 0.240 & 0.401 & 0.187 & 0.041 & $<0.001$ \\
\hline Nationality: IT & -0.133 & 0.021 & $<0.001$ & -0.044 & 0.206 & 0.830 & -0.107 & 0.038 & 0.005 \\
\hline Nationality: MA & 0.073 & 0.029 & 0.012 & 0.082 & 0.240 & 0.732 & 0.020 & 0.039 & 0.600 \\
\hline Nationality: NL & 0.055 & 0.023 & 0.018 & 0.036 & 0.190 & 0.848 & -0.009 & 0.036 & 0.807 \\
\hline Age & 0.001 & 0.001 & 0.027 & 0.001 & 0.004 & 0.792 & 0.001 & 0.001 & 0.044 \\
\hline Higher Education & 0.126 & 0.016 & $<0.001$ & 0.150 & 0.140 & 0.282 & 0.130 & 0.023 & $<0.001$ \\
\hline Professional Activity & 0.079 & 0.017 & $<0.001$ & 0.131 & 0.139 & 0.347 & 0.126 & 0.022 & $<0.001$ \\
\hline Net monthly HH income: $1500-3999 €$ & -0.030 & 0.020 & 0.130 & -0.044 & 0.156 & 0.779 & -0.058 & 0.027 & 0.030 \\
\hline Net monthly HH income: $>=4000 €$ & -0.099 & 0.026 & $<0.001$ & -0.096 & 0.218 & 0.660 & -0.115 & 0.034 & 0.001 \\
\hline Net monthly HH income: undeclared & -0.247 & 0.031 & $<0.001$ & -0.306 & 0.245 & 0.211 & -0.320 & 0.039 & $<0.001$ \\
\hline Household size & -0.038 & 0.007 & $<0.001$ & -0.041 & 0.059 & 0.487 & -0.041 & 0.010 & $<0.001$ \\
\hline Companion & 0.044 & 0.018 & 0.014 & 0.027 & 0.144 & 0.853 & 0.020 & 0.024 & 0.402 \\
\hline \multicolumn{10}{|l|}{ Residential characteristics } \\
\hline Urbanization residence: Urban & -0.039 & 0.018 & 0.032 & -0.139 & 0.152 & 0.360 & -0.121 & 0.025 & $<0.001$ \\
\hline HH dwelling ownership & -0.055 & 0.018 & 0.002 & -0.137 & 0.142 & 0.336 & -0.121 & 0.022 & $<0.001$ \\
\hline HH dwelling is detached house & 0.087 & 0.019 & $<0.001$ & 0.167 & 0.171 & 0.329 & 0.134 & 0.029 & $<0.001$ \\
\hline \multicolumn{10}{|l|}{ Transport options and mode use } \\
\hline Season ticket for public transport & 0.231 & 0.019 & $<0.001$ & 0.315 & 0.165 & 0.056 & 0.317 & 0.027 & $<0.001$ \\
\hline Car driving license & 0.253 & 0.024 & $<0.001$ & 0.238 & 0.210 & 0.257 & 0.264 & 0.032 & $<0.001$ \\
\hline Mobility restraints & -0.111 & 0.022 & $<0.001$ & -0.212 & 0.211 & 0.314 & -0.188 & 0.035 & $<0.001$ \\
\hline Bike possession & 0.277 & 0.017 & $<0.001$ & 0.298 & 0.148 & 0.044 & 0.311 & 0.022 & $<0.001$ \\
\hline Frequent walking & 0.117 & 0.017 & $<0.001$ & 0.165 & 0.141 & 0.241 & 0.166 & 0.025 & $<0.001$ \\
\hline Frequent public transit use & 0.210 & 0.018 & $<0.001$ & 0.216 & 0.153 & 0.158 & 0.219 & 0.026 & $<0.001$ \\
\hline Frequent car use & 0.182 & 0.019 & $<0.001$ & 0.089 & 0.151 & 0.558 & 0.112 & 0.024 & $<0.001$ \\
\hline \multicolumn{10}{|l|}{ Temporal characteristics } \\
\hline Weekend day & -0.068 & 0.016 & $<0.001$ & -0.028 & 0.142 & 0.841 & -0.020 & 0.023 & 0.380 \\
\hline \multicolumn{10}{|l|}{ Model specific parameters } \\
\hline Dispersion $^{1}$ & 0.005 & 0.000 & $<0.001$ & & & & & & \\
\hline Dispersion $^{2}$ & 0.186 & 0.003 & $<0.001$ & & & & & & \\
\hline Dispersion $^{3}$ & & & & 0.440 & 0.049 & $<0.001$ & 0.502 & 0.009 & $<0.001$ \\
\hline
\end{tabular}

\subsection{Motive Specific Travel Time Expenditures}

\subsubsection{Daily Travel Time Expenditure Commuting Trips}

With regard to the motive specific travel time expenditures, parameter estimates of the model predicting travel time expenditure on commuting (work/school) trips are displayed in Table 6. Recall that the motive specific models have two sets of parameters. The first set relates to the parameters estimating the effect on the mean parameter (negative binomial part), whereas the second set relates to the zero-inflation part.

Focusing on the socio-demographics, one could observe from the estimates of nationality that Spanish, French and Italian travelers spend significantly more time on commuting trips in comparison to Belgians. This can be explained by the fact that they are prepared to commute longer distances to find a job that matches their education. With regard to age, one can depict that on the one hand, age has an increasing effect on the mean travel time expenditure, whereas on the other hand it increases the probability of a zero travel time expenditure. Concerning gender, one can observe that it decreases the overall travel time expenditure and moreover increases the probability of a zero travel time expenditure. This negative effect 
1 provides evidence for two phenomena: ( $i$ ) a lower professional participation rate among females, (ii) a better 2 job-housing balance of females, as the female proportion of caretakers of children is still higher than males

3 due to the presence of traditional role patterns.

4

TABLE 5 Maximum Likelihood Parameter Estimates Zero-Inflated Negative Binomial Regression Model Daily Travel Time Expenditure Commuting Trips

\begin{tabular}{|c|c|c|c|c|c|c|c|c|c|}
\hline \multirow[b]{2}{*}{ Parameter } & \multicolumn{3}{|c|}{ Weighting } & \multicolumn{3}{|c|}{ Cons. bootstrapping } & \multicolumn{3}{|c|}{ Prog. bootstrapping } \\
\hline & Est. & S.E. & Sign. & Est. & S.E. & Sign. & Est. & S.E. & Sign. \\
\hline \multicolumn{10}{|l|}{ Negative binomial part } \\
\hline Intercept & 3.371 & 0.060 & $<0.001$ & 3.575 & 0.581 & $<0.001$ & 3.631 & 0.078 & $<0.001$ \\
\hline Nationality: ES & 0.127 & 0.040 & 0.002 & 0.258 & 0.319 & 0.419 & 0.196 & 0.047 & $<0.001$ \\
\hline Nationality: FR & 0.112 & 0.026 & $<0.001$ & 0.193 & 0.300 & 0.520 & 0.159 & 0.046 & 0.001 \\
\hline Nationality: IT & 0.105 & 0.030 & 0.001 & 0.181 & 0.323 & 0.575 & 0.140 & 0.052 & 0.007 \\
\hline Nationality: MA & -0.019 & 0.044 & 0.667 & -0.039 & 0.323 & 0.903 & -0.072 & 0.048 & 0.136 \\
\hline Nationality: NL & 0.061 & 0.036 & 0.095 & 0.075 & 0.338 & 0.824 & 0.033 & 0.049 & 0.506 \\
\hline Age & 0.008 & 0.001 & $<0.001$ & 0.013 & 0.009 & 0.139 & 0.012 & 0.001 & $<0.001$ \\
\hline Gender: Female & -0.148 & 0.020 & $<0.001$ & -0.111 & 0.167 & 0.505 & -0.122 & 0.024 & $<0.001$ \\
\hline Higher Education & 0.122 & 0.024 & $<0.001$ & 0.099 & 0.215 & 0.645 & 0.086 & 0.029 & 0.003 \\
\hline Net monthly HH income: $1500-3999 €$ & 0.095 & 0.033 & 0.004 & 0.202 & 0.278 & 0.466 & 0.178 & 0.037 & $<0.001$ \\
\hline Net monthly HH income: $>=4000 €$ & -0.075 & 0.038 & 0.050 & 0.016 & 0.321 & 0.961 & -0.037 & 0.045 & 0.415 \\
\hline Net monthly HH income: undeclared & 0.050 & 0.043 & 0.248 & 0.085 & 0.373 & 0.820 & 0.066 & 0.047 & 0.160 \\
\hline Companion & 0.073 & 0.024 & 0.002 & 0.038 & 0.212 & 0.856 & 0.049 & 0.028 & 0.082 \\
\hline Urbanization residence: Urban & -0.203 & 0.024 & $<0.001$ & -0.400 & 0.231 & 0.084 & -0.363 & 0.032 & $<0.001$ \\
\hline HH dwelling ownership & -0.145 & 0.025 & $<0.001$ & -0.198 & 0.203 & 0.331 & -0.181 & 0.031 & $<0.001$ \\
\hline HH dwelling is detached house & 0.093 & 0.026 & $<0.001$ & 0.021 & 0.253 & 0.935 & 0.041 & 0.038 & 0.283 \\
\hline Season ticket for public transport & 0.137 & 0.028 & $<0.001$ & 0.126 & 0.272 & 0.644 & 0.091 & 0.033 & 0.006 \\
\hline Car driving license & 0.170 & 0.033 & $<0.001$ & 0.026 & 0.327 & 0.936 & 0.044 & 0.043 & 0.306 \\
\hline Bike possession & 0.111 & 0.025 & $<0.001$ & 0.137 & 0.215 & 0.524 & 0.145 & 0.030 & $<0.001$ \\
\hline Car possession & 0.152 & 0.032 & $<0.001$ & -0.103 & 0.273 & 0.707 & -0.084 & 0.036 & 0.019 \\
\hline Frequent walking & -0.139 & 0.023 & $<0.001$ & -0.204 & 0.194 & 0.293 & -0.191 & 0.027 & $<0.001$ \\
\hline Frequent public transit use & 0.524 & 0.028 & $<0.001$ & 0.459 & 0.265 & 0.084 & 0.479 & 0.036 & $<0.001$ \\
\hline Travel time expenditure & -0.001 & 0.000 & $<0.001$ & -0.002 & 0.002 & 0.412 & -0.001 & 0.000 & $<0.001$ \\
\hline Dispersion $^{1}$ & 0.004 & 0.000 & $<0.001$ & & & & & & \\
\hline Dispersion $^{2}$ & 0.135 & 0.004 & $<0.001$ & & & & & & \\
\hline Dispersion $^{3}$ & & & & 0.310 & 0.053 & $<0.001$ & 0.408 & 0.009 & $<0.001$ \\
\hline \multicolumn{10}{|l|}{ Zero-inflated part } \\
\hline Intercept & -1.507 & 0.221 & $<0.001$ & -2.358 & 1.540 & 0.126 & -2.148 & 0.194 & $<0.001$ \\
\hline Age & 0.052 & 0.003 & $<0.001$ & 0.065 & 0.022 & 0.003 & 0.059 & 0.003 & $<0.001$ \\
\hline Gender: Female & 0.372 & 0.068 & $<0.001$ & 0.102 & 0.547 & 0.852 & 0.078 & 0.073 & 0.289 \\
\hline Professional Activity & -2.767 & 0.092 & $<0.001$ & -3.358 & 0.777 & $<0.001$ & -3.023 & 0.097 & $<0.001$ \\
\hline Household size & -0.163 & 0.037 & $<0.001$ & -0.138 & 0.245 & 0.572 & -0.117 & 0.032 & $<0.001$ \\
\hline Companion & 0.417 & 0.091 & $<0.001$ & 0.596 & 0.681 & 0.381 & 0.496 & 0.095 & $<0.001$ \\
\hline Having child(ren) & 0.413 & 0.106 & $<0.001$ & 0.553 & 0.842 & 0.511 & 0.479 & 0.113 & $<0.001$ \\
\hline Urbanization residence: Urban & -0.162 & 0.071 & 0.023 & -0.125 & 0.647 & 0.847 & -0.086 & 0.082 & 0.290 \\
\hline Season ticket for public transport & -0.268 & 0.105 & 0.011 & -0.923 & 0.744 & 0.215 & -0.814 & 0.092 & $<0.001$ \\
\hline Car possession & -0.403 & 0.136 & 0.003 & -0.333 & 0.743 & 0.654 & -0.337 & 0.101 & 0.001 \\
\hline Frequent public transit use & -0.234 & 0.102 & 0.021 & -0.315 & 0.736 & 0.668 & -0.306 & 0.092 & 0.001 \\
\hline Weekend day & 2.907 & 0.088 & $<0.001$ & 3.406 & 0.826 & $<0.001$ & 3.105 & 0.106 & $<0.001$ \\
\hline School holiday & 1.415 & 0.090 & $<0.001$ & 1.746 & 0.835 & 0.037 & 1.605 & 0.110 & $<0.001$ \\
\hline Travel time expenditure other & 0.014 & 0.001 & $<0.001$ & 0.026 & 0.009 & 0.003 & 0.023 & 0.001 & $<0.001$ \\
\hline
\end{tabular}


An obvious, but very significant effect is the decreased likelihood of a zero travel time expenditure on commuting trips when the traveler is professionally active. In the same context, the temporal characteristics (i.e. weekend day and school holiday) significantly affect the probability of a zero travel time expenditure.

In addition, the increasing effect of frequent public transit use draws attention. This effect can be partially explained by the fact that travelers, who use the train for their work commute, typically travel longer distances and have correspondingly longer travel times.

\subsubsection{Daily Travel Time Expenditure Shopping Trips}

Parameter estimates of the model predicting daily travel time expenditure on shopping trips are displayed in Table 6. The strongest effects with respect to nationality are the considerable higher travel time expenditure of Moroccans and lower expenditure of Italians in comparison to Belgians. The higher daily travel time for shopping for Spanish and Moroccans can be explained by distance between their residence and the shopping locations that correspond to the own food preferences. This could be an index of social exclusion or low integration of these national groups in the Belgian society (9).

Regarding other socio-demographics, especially the gender difference is appealing. Females have a higher mean travel time expenditure and a lower probability of a zero travel time expenditure in comparison to males. This provides evidence that the general preoccupation that shopping is mainly a female activity holds true.

\subsubsection{Daily Travel Time Expenditure Leisure Trips}

Regarding the parameter estimates of the leisure trip model (displayed in Table 7), one could depict that especially Dutch and Moroccans are spending less time on leisure trips in comparison to Belgians. A possible explanation for the Moroccans is that they are more committed toward their original cultural traditions, and therefore prefer to spend leisure time with their countrymen, which are often geographically clustered. Furthermore, one could see that the above mentioned effect of owning a dwelling in comparison to be tenant, and the effect of higher education play an important role in the context of leisure trips. Concerning temporal characteristics, one can see that leisure trips are especially a weekend day activity, since the probability of zero travel time expenditure is considerably lower during weekends. 
1 TABLE 6 Maximum Likelihood Parameter Estimates Zero-Inflated Negative Binomial Regression Model

2 Daily Travel Time Expenditure Shopping Trips

\begin{tabular}{|c|c|c|c|c|c|c|c|c|c|}
\hline \multirow[b]{2}{*}{ Parameter } & \multicolumn{3}{|c|}{ Weighting } & \multicolumn{3}{|c|}{ Cons. bootstrapping } & \multicolumn{3}{|c|}{ Prog. bootstrapping } \\
\hline & Est. & S.E. & Sign. & Est. & S.E. & Sign. & Est. & S.E. & Sign. \\
\hline \multicolumn{10}{|l|}{ Negative binomial part } \\
\hline Intercept & 2.513 & 0.096 & $<0.001$ & 1.688 & 0.956 & 0.077 & 2.046 & 0.138 & $<0.001$ \\
\hline Nationality: ES & -0.124 & 0.056 & 0.028 & -0.078 & 0.519 & 0.881 & -0.325 & 0.097 & 0.001 \\
\hline Nationality: FR & 0.243 & 0.042 & $<0.001$ & 0.406 & 0.533 & 0.447 & 0.221 & 0.093 & 0.017 \\
\hline Nationality: IT & -0.298 & 0.047 & $<0.001$ & -0.199 & 0.558 & 0.722 & -0.385 & 0.093 & $<0.001$ \\
\hline Nationality: MA & 0.569 & 0.060 & $<0.001$ & 0.882 & 0.548 & 0.108 & 0.615 & 0.091 & $<0.001$ \\
\hline Nationality: NL & 0.132 & 0.053 & 0.013 & 0.325 & 0.473 & 0.492 & 0.054 & 0.091 & 0.548 \\
\hline Age & 0.008 & 0.001 & $<0.001$ & 0.016 & 0.009 & 0.071 & 0.016 & 0.002 & $<0.001$ \\
\hline Gender: Female & 0.129 & 0.029 & $<0.001$ & 0.181 & 0.247 & 0.463 & 0.187 & 0.045 & $<0.001$ \\
\hline Net monthly HH & -0.207 & 0.043 & $<0.001$ & -0.372 & 0.436 & 0.393 & -0.355 & 0.058 & $<0.001$ \\
\hline Net monthly HH income: $>=4000 €$ & -0.451 & 0.056 & $<0.001$ & -0.654 & 0.551 & 0.235 & -0.668 & 0.081 & $<0.001$ \\
\hline Net monthly HH income: undeclared & -0.240 & 0.067 & $<0.001$ & -0.250 & 0.593 & 0.673 & -0.268 & 0.067 & $<0.001$ \\
\hline Household size & 0.091 & 0.018 & $<0.001$ & 0.063 & 0.184 & 0.731 & 0.081 & 0.040 & 0.045 \\
\hline Having child(ren) & -0.416 & 0.045 & $<0.001$ & -0.500 & 0.534 & 0.349 & -0.534 & 0.099 & $<0.001$ \\
\hline Urbanization residence: Urban & -0.120 & 0.038 & 0.001 & -0.123 & 0.400 & 0.759 & -0.183 & 0.063 & 0.003 \\
\hline HH dwelling ownership & -0.093 & 0.036 & 0.010 & -0.237 & 0.284 & 0.405 & -0.221 & 0.042 & $<0.001$ \\
\hline HH dwelling is detached & 0.141 & 0.040 & $<0.001$ & 0.377 & 0.448 & 0.399 & 0.286 & 0.067 & $<0.001$ \\
\hline Season ticket for public transport & 0.168 & 0.042 & $<0.001$ & 0.184 & 0.342 & 0.590 & 0.153 & 0.065 & 0.020 \\
\hline Car dr & 0.122 & 0.049 & 0.012 & 0.281 & 0.566 & 0.620 & 0.217 & 0.076 & 0.004 \\
\hline Mobility restraints & -0.224 & 0.049 & $<0.001$ & -0.393 & 0.571 & 0.491 & -0.449 & 0.091 & $<0.001$ \\
\hline Car possession & 0.512 & 0.051 & $<0.001$ & 0.855 & 0.475 & 0.072 & 0.841 & 0.067 & $<0.001$ \\
\hline Frequent walking & 0.153 & 0.037 & $<0.001$ & 0.215 & 0.388 & 0.579 & 0.183 & 0.050 & $<0.001$ \\
\hline Freque & 0.106 & 0.039 & 0.006 & -0.162 & 0.346 & 0.639 & -0.096 & 0.076 & 0.205 \\
\hline ublic tr & 0.343 & 0.039 & $<0.001$ & 0.444 & 0.323 & 0.169 & 0.476 & 0.059 & $<0.001$ \\
\hline Dispe & 0.006 & 0.000 & $<0.001$ & & & & & & \\
\hline Dispersion $^{2}$ & 0.199 & 0.008 & $<0.001$ & & & & & & \\
\hline Dispersion $^{3}$ & & & & 0.257 & 0.085 & 0.003 & 0.446 & 0.025 & $<0.001$ \\
\hline \multicolumn{10}{|l|}{ Zero-Inflation part } \\
\hline Intercept & 0.891 & 0.180 & $<0.001$ & 1.640 & 1.243 & 0.187 & 1.516 & 0.166 & $<0.001$ \\
\hline Age & -0.019 & 0.002 & $<0.001$ & -0.029 & 0.013 & 0.034 & -0.026 & 0.002 & $<0.001$ \\
\hline Gender: Female & -0.295 & 0.055 & $<0.001$ & -0.240 & 0.400 & 0.548 & -0.229 & 0.059 & $<0.001$ \\
\hline Higher Education & -0.496 & 0.060 & $<0.001$ & -0.520 & 0.486 & 0.284 & -0.473 & 0.065 & $<0.001$ \\
\hline Professional Activity & 0.527 & 0.069 & $<0.001$ & 0.449 & 0.487 & 0.357 & 0.433 & 0.066 & $<0.001$ \\
\hline Household size & 0.146 & 0.033 & $<0.001$ & 0.401 & 0.216 & 0.063 & 0.379 & 0.032 & $<0.001$ \\
\hline Having child(ren) & -0.499 & 0.086 & $<0.001$ & -0.934 & 0.599 & 0.119 & -0.860 & 0.086 & $<0.001$ \\
\hline Season ticket for pul & 0.184 & 0.073 & 0.011 & -0.379 & 0.464 & 0.414 & -0.329 & 0.062 & $<0.001$ \\
\hline Car driving license & -0.312 & 0.092 & 0.001 & -0.007 & 0.532 & 0.989 & -0.009 & 0.080 & 0.912 \\
\hline Bike possession & -0.155 & 0.067 & 0.021 & -0.733 & 0.469 & 0.118 & -0.684 & 0.068 & $<0.001$ \\
\hline Car possession & 0.512 & 0.103 & $<0.001$ & 0.011 & 0.549 & 0.984 & 0.029 & 0.071 & 0.685 \\
\hline Frequent walking & -0.182 & 0.060 & 0.003 & -0.413 & 0.544 & 0.448 & -0.398 & 0.075 & $<0.001$ \\
\hline Weekend day & -0.370 & 0.063 & $<0.001$ & -0.773 & 0.458 & 0.092 & -0.750 & 0.064 & $<0.001$ \\
\hline School holiday & -0.265 & 0.074 & $<0.001$ & -0.012 & 0.513 & 0.981 & -0.041 & 0.076 & 0.595 \\
\hline Travel time expenditure other & 0.010 & 0.001 & $<0.001$ & 0.012 & 0.005 & 0.021 & 0.011 & 0.001 & $<0.001$ \\
\hline
\end{tabular}


TABLE 7 Maximum Likelihood Parameter Estimates Zero-Inflated Negative Binomial Regression Model

2 Daily Travel Time Expenditure Leisure Trips

\begin{tabular}{|c|c|c|c|c|c|c|c|c|c|}
\hline \multirow[b]{2}{*}{ Parameter } & \multicolumn{3}{|c|}{ Weighting } & \multicolumn{3}{|c|}{ Cons. bootstrapping } & \multicolumn{3}{|c|}{ Prog. bootstrapping } \\
\hline & Est. & S.E. & Sign. & Est. & S.E. & Sign. & Est. & S.E. & Sign. \\
\hline \multicolumn{10}{|l|}{ Negative binomial part } \\
\hline Intercept & 3.768 & 0.136 & $<0.001$ & 3.406 & 2.934 & 0.246 & 3.791 & 0.192 & $<0.001$ \\
\hline Nationality: ES & -0.304 & 0.101 & 0.003 & -0.176 & 1.938 & 0.928 & -0.549 & 0.140 & $<0.001$ \\
\hline Nationality: FR & -0.298 & 0.067 & $<0.001$ & -0.172 & 1.340 & 0.898 & -0.442 & 0.104 & $<0.001$ \\
\hline Nationality: IT & 0.091 & 0.075 & 0.224 & 0.432 & 2.323 & 0.852 & 0.152 & 0.124 & 0.219 \\
\hline Nationality: MA & -0.569 & 0.152 & $<0.001$ & -0.627 & 7.807 & 0.936 & -0.887 & 0.148 & $<0.001$ \\
\hline Nationality: NL & -0.761 & 0.073 & $<0.001$ & -0.462 & 1.027 & 0.652 & -0.896 & 0.109 & $<0.001$ \\
\hline Age & 0.006 & 0.002 & $<0.001$ & 0.010 & 0.031 & 0.754 & 0.008 & 0.002 & 0.001 \\
\hline nale & 0.208 & 0.045 & $<0.001$ & 0.284 & 0.945 & 0.764 & 0.243 & 0.061 & $<0.001$ \\
\hline Higher Education & 0.141 & 0.057 & 0.014 & 0.321 & 1.049 & 0.760 & 0.248 & 0.080 & 0.002 \\
\hline Household size & -0.045 & 0.021 & 0.035 & -0.010 & 0.335 & 0.977 & -0.017 & 0.024 & 0.466 \\
\hline Companion & 0.193 & 0.063 & 0.002 & 0.122 & 1.003 & 0.903 & 0.197 & 0.073 & 0.007 \\
\hline HH dwelling ownership & -0.466 & 0.064 & $<0.001$ & -0.716 & 0.968 & 0.459 & -0.703 & 0.066 & $<0.001$ \\
\hline $\mathrm{HH}$ dwelling is detached house & 0.220 & 0.058 & $<0.001$ & 0.192 & 1.184 & 0.872 & 0.212 & 0.098 & 0.030 \\
\hline Seaso & 0.191 & 0.055 & 0.001 & 0.142 & 0.901 & 0.875 & 0.161 & 0.073 & 0.027 \\
\hline Car dr & -0.232 & 0.072 & 0.001 & -0.530 & 1.242 & 0.669 & -0.496 & 0.092 & $<0.001$ \\
\hline Car $\mathrm{p}$ & 0.403 & 0.086 & $<0.001$ & 0.707 & 1.633 & 0.665 & 0.676 & 0.097 & $<0.001$ \\
\hline Freque & 0.464 & 0.053 & $<0.001$ & 0.546 & 0.965 & 0.572 & 0.620 & 0.086 & $<0.001$ \\
\hline Frequent car use & -0.350 & 0.069 & $<0.001$ & -0.552 & 1.340 & 0.680 & -0.516 & 0.077 & $<0.001$ \\
\hline Weekend day & 0.126 & 0.052 & 0.014 & 0.166 & 0.893 & 0.852 & 0.156 & 0.080 & 0.052 \\
\hline Dispe & 0.006 & 0.000 & $<0.001$ & & & & & & \\
\hline Disp & 0.211 & 0.011 & $<0.001$ & & & & & & \\
\hline Dispersion $^{3}$ & & & & 0.093 & 0.075 & 0.217 & 0.318 & 0.026 & $<0.001$ \\
\hline \multicolumn{10}{|l|}{ Zero-Inflation pa } \\
\hline Intercept & 1.813 & 0.179 & $<0.001$ & 1.554 & 1.024 & 0.129 & 1.478 & 0.149 & $<0.001$ \\
\hline Age & 0.008 & 0.002 & $<0.001$ & 0.021 & 0.017 & 0.207 & 0.019 & 0.002 & $<0.001$ \\
\hline Gend & 0.168 & 0.067 & 0.012 & 0.800 & 0.574 & 0.163 & 0.745 & 0.075 & $<0.001$ \\
\hline Highe & -0.506 & 0.077 & $<0.001$ & -0.839 & 0.637 & 0.188 & -0.742 & 0.087 & $<0.001$ \\
\hline Net $\mathrm{m}$ & -0.323 & 0.106 & 0.002 & -0.063 & 0.647 & 0.923 & -0.067 & 0.090 & 0.458 \\
\hline$:>=4000 €$ & -0.587 & 0.123 & $<0.001$ & 0.012 & 0.857 & 0.988 & -0.017 & 0.112 & 0.880 \\
\hline Net monthly HH income: undeclared & 0.086 & 0.176 & 0.627 & 0.624 & 6.258 & 0.921 & 0.556 & 0.150 & $<0.001$ \\
\hline Professional Activity & 0.398 & 0.080 & $<0.001$ & 0.833 & 0.661 & 0.208 & 0.763 & 0.086 & $<0.001$ \\
\hline Having child(ren) & 0.299 & 0.088 & 0.001 & -0.219 & 0.714 & 0.759 & -0.142 & 0.089 & 0.112 \\
\hline Season ticket for $\mathrm{pt}$ & -0.324 & 0.081 & $<0.001$ & -1.037 & 0.680 & 0.127 & -0.898 & 0.082 & $<0.001$ \\
\hline Bike possession & -0.181 & 0.091 & 0.046 & 0.344 & 0.695 & 0.620 & 0.314 & 0.095 & 0.001 \\
\hline Frequent cycling & -0.244 & 0.080 & 0.002 & -1.422 & 0.656 & 0.030 & -1.273 & 0.082 & $<0.001$ \\
\hline Frequent car use & -0.350 & 0.108 & 0.001 & -0.396 & 0.730 & 0.588 & -0.299 & 0.083 & $<0.001$ \\
\hline Weekend day & -0.583 & 0.071 & $<0.001$ & -1.314 & 0.573 & 0.022 & -1.167 & 0.071 & $<0.001$ \\
\hline Travel time expenditure other & 0.008 & 0.001 & $<0.001$ & 0.006 & 0.005 & 0.310 & 0.004 & 0.001 & $<0.001$ \\
\hline
\end{tabular}

${ }^{1}$ Conservative weighting, ${ }^{2}$ Progressive weighting, ${ }^{3}$ Bootstrapping

\subsubsection{Daily Travel Time Expenditure Visit Trips}

A final set of parameters corresponds to the parameters of the model predicting travel time expenditure on visit trips. From Table 8, one could see that Spanish and Italians spend considerable less time on visit trips in comparison to Belgians, whereas French spend significantly more time. This can be partially explained by the fact that Belgian and French people have a higher probability of having family or close friends living in Belgium or in the same city, whereas Spanish and Italian groups have a lower probability. Moreover, for French people, it is still reasonable to visit relatives and friends in France given the geographical proximity, 
1 whereas this is less likely for Italians and Spanish. Besides, one should notice the effect of school holidays, 2 which has an increasing effect on overall travel time expenditure and a decreasing effect on the likelihood 3 of a zero expenditure.

4

TABLE 8 Maximum Likelihood Parameter Estimates Zero-Inflated Negative Binomial Regression Model Daily Travel Time Expenditure Visit Trips

\begin{tabular}{|c|c|c|c|c|c|c|c|c|c|}
\hline \multirow[b]{2}{*}{ Parameter } & \multicolumn{3}{|c|}{ Weighting } & \multicolumn{3}{|c|}{ Cons. bootstrapping } & \multicolumn{3}{|c|}{ Prog. bootstrapping } \\
\hline & Est. & S.E. & Sign. & Est. & S.E. & Sign. & Est. & S.E. & Sign. \\
\hline \multicolumn{10}{|l|}{ Negative binomial part } \\
\hline Intercept & 1.682 & 0.132 & $<0.001$ & 0.899 & 2.885 & 0.755 & 1.248 & 0.233 & $<0.001$ \\
\hline Nationality: ES & -0.870 & 0.103 & $<0.001$ & -0.625 & 1.532 & 0.683 & -1.241 & 0.121 & $<0.001$ \\
\hline Nationality: FR & 0.553 & 0.062 & $<0.001$ & 0.527 & 1.388 & 0.704 & 0.276 & 0.111 & 0.013 \\
\hline Nationality: IT & -0.651 & 0.074 & $<0.001$ & -0.470 & 1.474 & 0.750 & -0.881 & 0.120 & $<0.001$ \\
\hline Nationality: MA & -0.042 & 0.106 & 0.688 & 0.112 & 1.952 & 0.954 & -0.237 & 0.135 & 0.079 \\
\hline Nationality: NL & 0.240 & 0.082 & 0.003 & 0.313 & 1.516 & 0.837 & 0.110 & 0.124 & 0.375 \\
\hline Age & 0.015 & 0.001 & $<0.001$ & 0.015 & 0.030 & 0.606 & 0.017 & 0.002 & $<0.001$ \\
\hline Gender: Female & 0.201 & 0.045 & $<0.001$ & 0.364 & 0.780 & 0.640 & 0.294 & 0.072 & $<0.001$ \\
\hline Higher Education & 0.243 & 0.047 & $<0.001$ & 0.189 & 0.810 & 0.816 & 0.290 & 0.062 & $<0.001$ \\
\hline Net monthly HH income: $1500-3999 €$ & -0.052 & 0.063 & 0.414 & 0.112 & 1.145 & 0.922 & 0.084 & 0.093 & 0.365 \\
\hline Net monthly HH income: $>=4000 €$ & -0.178 & 0.087 & 0.041 & -0.060 & 1.771 & 0.973 & -0.112 & 0.123 & 0.363 \\
\hline Net monthly HH income: undeclared & -0.524 & 0.132 & $<0.001$ & -4.975 & 8.348 & 0.551 & -0.915 & 0.401 & 0.023 \\
\hline Hou: & 0.150 & 0.028 & $<0.001$ & 0.193 & 0.529 & 0.715 & 0.137 & 0.037 & $<0.001$ \\
\hline Havi & -0.501 & 0.069 & $<0.001$ & -0.409 & 1.343 & 0.761 & -0.422 & 0.113 & $<0.001$ \\
\hline Urbaniz & 0.820 & 0.057 & $<0.001$ & 1.222 & 1.052 & 0.245 & 1.210 & 0.086 & $<0.001$ \\
\hline HH dwelling ownership & 0.237 & 0.057 & $<0.001$ & 0.202 & 1.382 & 0.884 & 0.335 & 0.084 & $<0.001$ \\
\hline Season ticket for public transport & 0.319 & 0.058 & $<0.001$ & 0.053 & 1.088 & 0.961 & 0.245 & 0.095 & 0.010 \\
\hline Car driving license & 0.212 & 0.067 & 0.002 & 0.257 & 1.227 & 0.834 & 0.259 & 0.088 & 0.003 \\
\hline Bike p & 0.244 & 0.052 & $<0.001$ & 0.161 & 0.926 & 0.862 & 0.215 & 0.064 & 0.001 \\
\hline Week & 0.245 & 0.053 & $<0.001$ & 0.493 & 1.123 & 0.661 & 0.461 & 0.084 & $<0.001$ \\
\hline School & 0.450 & 0.061 & $<0.001$ & 0.394 & 1.297 & 0.761 & 0.389 & 0.102 & $<0.001$ \\
\hline Travel time & -0.001 & 0.000 & 0.001 & -0.001 & 0.009 & 0.931 & -0.001 & 0.001 & 0.470 \\
\hline Dispersion $^{1}$ & 0.008 & 0.000 & $<0.001$ & & & & & & \\
\hline Dispersion $^{2}$ & 0.284 & 0.016 & $<0.001$ & & & & & & \\
\hline Dispersion $^{3}$ & & & & 0.159 & 0.109 & 0.145 & 0.512 & 0.032 & $<0.001$ \\
\hline \multicolumn{10}{|l|}{ Zero-Inflation part } \\
\hline Interce & 1.056 & 0.147 & $<0.001$ & 0.759 & 1.176 & 0.519 & 0.790 & 0.163 & $<0.001$ \\
\hline Higher Education & -0.173 & 0.069 & 0.013 & 0.257 & 0.556 & 0.645 & 0.204 & 0.081 & 0.012 \\
\hline Professional Activity & 0.297 & 0.070 & $<0.001$ & 0.386 & 0.537 & 0.473 & 0.302 & 0.071 & $<0.001$ \\
\hline Household size & 0.090 & 0.028 & 0.001 & 0.082 & 0.236 & 0.727 & 0.089 & 0.033 & 0.006 \\
\hline Companion & 0.234 & 0.070 & 0.001 & 0.033 & 0.576 & 0.954 & 0.051 & 0.072 & 0.478 \\
\hline Urbanization residence: Urban & 0.220 & 0.065 & 0.001 & 0.849 & 0.547 & 0.120 & 0.728 & 0.077 & $<0.001$ \\
\hline Car driving license & -0.320 & 0.098 & 0.001 & -0.477 & 0.771 & 0.536 & -0.409 & 0.094 & $<0.001$ \\
\hline Bike possession & -0.169 & 0.077 & 0.028 & -0.269 & 0.589 & 0.648 & -0.242 & 0.085 & 0.004 \\
\hline Car possession & 0.287 & 0.131 & 0.028 & 0.896 & 0.909 & 0.325 & 0.821 & 0.133 & $<0.001$ \\
\hline Frequent car use & -0.430 & 0.112 & $<0.001$ & -1.177 & 0.950 & 0.215 & -1.016 & 0.135 & $<0.001$ \\
\hline Weekend day & -0.927 & 0.070 & $<0.001$ & -0.829 & 0.591 & 0.161 & -0.798 & 0.080 & $<0.001$ \\
\hline School holiday & -0.678 & 0.083 & $<0.001$ & -0.562 & 0.724 & 0.438 & -0.471 & 0.091 & $<0.001$ \\
\hline Travel time expen & 0.011 & 0.001 & $<0.001$ & 0.014 & 0.007 & 0.034 & 0.013 & 0.001 & $<0.001$ \\
\hline
\end{tabular}




\section{CONCLUSIONS}

The results of the different models indicate that nationality plays an important role in explaining differences in daily travel time expenditure. Even after controlling for other contributing factors, such as sociodemographics, residential characteristics, transport options and temporal characteristics, nationality still has a significant effect. This finding is especially relevant in the development of policy packages that are targeted to tackle social inequalities.

From a methodological perspective, different methodological options, i.e. two weighting schemes and two bootstrap solutions, were presented to provide sufficient support for the conclusions. The progressive bootstrapping approach detects easier differences and significant in comparison to the conservative bootstrapping approach which only identifies the key variable. Yet, it identifies a smaller number of significant effects than the weighting approaches. Thus, the progressive bootstrapping approach balances the ability to depict significant differences and simplicity of the model.

To ensure the required level of generalizability of the results in further studies, an oversampling of travelers with a different nationality is strongly recommended. Moreover, the methods that are presented enable to depict the real differences in travel time expenditure among different nationalities. Take as an example the expenditure on commuting trips. From Table 1, one gets the impression that Italians spend less time on commuting then Belgians, whereas after correcting for different explanatory factors one can observe From Tables 3 and 5 that they are spending significantly more time on commuting.

In this paper, nationality was used as an indicator for assessing ethnic diversity. Although commonly used in ethnic research, other more refined indicators should be collected to more precisely refine the results. Moreover, future research should focus more on the underlying psychological constructs of why ethnic and cultural differences persist, even if one accounts for other determinants. In this context, the use of cultural dimension scales seems to be an interesting research direction. Besides, information about the size of ethnic communities as well as information about activity locations can provide additional insights in the context of visit and shopping trips.

\section{ACKNOWLEDGEMENTS}

This study was realized in the context of the project INTRAS (INequalities in TRAffic Safety) within the scope of the research program BRAIN (Belgian Research Action through Interdisciplinary Networks) funded by the Federal Public Planning Service Science Policy.

\section{REFERENCES}

1. Duyck, J., M. Englert, L. Masure, and J.-M. Paul. Bevolkingsvooruitzichten 2012-2060 [Demographic forecasts 2012-2060]. Federal Planning Bureau and Statistics Belgium, Brussels, 2013.

2. Van der Bracht, K., B. Van de Putte, P.-P. Verhaeghe, and K. Van Kerckem. Ethnic diversity in Belgium: old and new migration, old and new developments. Journal of Diversity and Gender Studies, Vol. 1, No. 1, 2015, pp. 73-81.

3. Chatman, D. G. Explaining the "immigrant effect" on auto use: the influences of neighborhoods and preferences. Transportation, Vol. 41, No. 3, May 2014, pp. 441-461.

4. Contrino, H., and N. McGuckin. Demographics Matter: Travel Demand, Options, and Characteristics Among Minority Populations. Public Works Management \& Policy, Vol. 13, No. 4, 2009, pp. 361-368.

5. Ma, L., and S. Srinivasan. Impact of Individuals' Immigrant Status on Household Auto Ownership. In Transportation Research Record: Journal of the Transportation Research Board, No. 2156, Transportation Research board of the National Academies, Washington, D.C., 2010, pp. 36-46.

6. Tal, G., and S. Handy. Travel behavior of immigrants: An analysis of the 2001 National Household Transportation Survey. Transport Policy, Vol. 17, No. 2, 2010, pp. 85-93. 
7. Bhat, C. R., R. Paleti, R. M. Pendyala, K. Lorenzini, and K. C. Konduri. Accommodating Immigration Status and Self-Selection Effects in a Joint Model of Household Auto Ownership and Residential Location Choice. In Transportation Research Record: Journal of the Transportation Research Board, No. 2382, Transportation Research board of the National Academies, Washington, D.C., 2013, pp. 142-150.

8. Volosin, S.E., S. Paul, K.P. Christian, K.C. Konduri, and R.M. Pendyala. Exploring the Dynamics in Travel Time Frontiers. In ransportation Research Record: Journal of the Transportation Research Board, No. 2382, Transportation Research board of the National Academies, Washington, D.C., 2013, pp. 20-27.

9. Farber, S., A. Páez, R.G. Mercado, M. Roorda, and C. Morency. A time-use investigation of shopping participation in three Canadian cities: is there evidence of social exclusion? Transportation, Vol. 38, No. 1, 2011, pp. 17-44.

10. Bhat, G., and R. B. Naumann. Travel-related behaviors, opinions, and concerns of U.S. adult drivers by race/ethnicity, 2010. Journal of Safety Research, Vol. 47, 2013, pp. 93-97.

11. Chatman, D. G., and N. J. Klein. Why do immigrants drive less? Confirmations, complications, and new hypotheses from a qualitative study in New Jersey, USA. Transport Policy, Vol. 30, 2013, pp. 336-344.

12. Smart, M. US immigrants and bicycling: Two-wheeled in Autopia. Transport Policy, Vol. 17, No. 3, 2010, pp. 153-159.

13. Bora, N., Y.-H.Chang, and R. Maheswaran. Mobility Patterns and User Dynamics in Racially Segregated Geographies of US Cities. In Kennedy W.G., N. Agarwal, and S.J. Yang (Eds.), Social Computing, Behavioral-Cultural Modeling and Prediction, Springer International Publishing, Cham, 2014, pp. 11-18.

14. Silm, S., and R. Ahas. Ethnic Differences in Activity Spaces: A Study of Out-of-Home Nonemployment Activities with Mobile Phone Data. Annals of the Association of American Geographers, Vol. 104, No. 3, 2014, pp. 542-559.

15. Kuebler, M., and J.S. Rugh, New evidence on racial and ethnic disparities in homeownership in the United States from 2001 to 2010. Social Science Research, Vol. 42, No. 5, 2013, pp. 1357-1374.

16. Banerjee, A., X. Ye, and R. Pendyala. Understanding Travel Time Expenditures Around the World: Exploring the Notion of a Travel Time Frontier. Transportation, Vol. 34, No. 1, 2007, pp. 51-65.

17. Ahmed, A., and P. Stopher. Seventy Minutes Plus or Minus 10 - A Review of Travel Time Budget Studies. Transport Reviews, Vol. 34, No. 5, Sep. 2014, pp. 607-625.

18. Chikaraishi, M., A. Fujiwara, J. Zhang, K.W. Axhausen, and D. Zumkeller. Changes in Variations of Travel Time Expenditure: Some Methodological Considerations and Empirical Results from German Mobility Panel. In Transportation Research Record: Journal of the Transportation Research Board, No. 2230, Transportation Research board of the National Academies, Washington, D.C., 2011, pp. 121-131.

19. Cools, M., E. Moons, and G. Wets. Assessing the Impact of Public Holidays on Travel Time Expenditure: Differentiation by Trip Motive. In Transportation Research Record: Journal of the Transportation Research Board, No. 2157, Transportation Research board of the National Academies, Washington, D.C., 2010, pp. 29-37.

20. Li, D., T. Miwa, and T. Morikawa. Analysis of Car Usage Time Frontiers Incorporating Both Interand Intraindividual Variation with GPS Data. In Transportation Research Record: Journal of the Transportation Research Board, No. 2413, Transportation Research board of the National Academies, Washington, D.C., 2014, pp. 13-23.

21. Raux, C., T.-Y. Ma, I. Joly, V. Kaufmann, E. Cornelis, and N. Ovtracht. Travel and activity time allocation: An empirical comparison between eight cities in Europe. Transport Policy, Vol. 18, No. 2, 2011, pp. 401-412.

22. Sharmeen, F., T. Arentze, and H. Timmermans. Incorporating Time Dynamics in Activity Travel Behavior Model: A Path Analysis of Changes in Activity and Travel Time Allocation in Response to Life-Cycle Events. In Transportation Research Record: Journal of the Transportation Research 
Board, No. 2382, Transportation Research board of the National Academies, Washington, D.C., 2013, pp. 54-62.

23. Susilo, Y.O., and M. Dijst. How Far Is Too Far? Travel Time Ratios for Activity Participation in the Netherlands. In Transportation Research Record: Journal of the Transportation Research Board, No. 2134, Transportation Research board of the National Academies, Washington, D.C., 2009, pp. 89-98.

24. Yang, D., and H. Timmermans. Analysis of influence of fuel price on individual activity-travel time expenditure. Transport Policy, Vol. 30, 2013, pp. 40-55.

25. Zong, F., J. Hongfei, P. Xiang, and W. Yang. Prediction of Commuter's Daily Time Allocation. PROMET - Traffic\&Transportation, Vol. 25, No. 5, 2013, pp. 445-455.

26. Cornelis, E., M. Hubert, P. Huynen, K. Lebrun, G. Patriarche, A. De Witte, L. Creemers, K. Declercq, D. Janssens, M. Castaigne, L. Hollaert, and F. Walle. Belgian Daily Mobility (BELDAM): Enquête sur la mobilité quotidienne des belges. SPF Mobilité \& Transports, Brussels, 2012.

27. Hubert, J.-P., J. Armoogum, K. W. Axhausen, and J.-L. Madre. Immobility and Mobility Seen Through Trip-Based Versus Time-Use Surveys. Transport Reviews, Vol. 28, No. 5, 2008, pp. 641658.

28. Hilbe, J.M. Negative Binomial Regression. Cambridge University Press, New York, 2007.

29. SAS Institute Inc. SAS/STAT 14.1 User's Guide. SAS Institute Inc, Cary, N.C., 2015.

30. Long, J.S. Regression Models for Categorical and Limited Dependent Variables. Sage Publications, Thousand Oaks, C.A., 1997.

31. Hesterberg, T., S. Monaghen, D.S. Moore, A. Clipson, and. R. Epstein. Bootstrap Methods and Permutation Tests. Companion Chapter 18 to the practice of Business Statistics. W.H. Freeman and Company, New York, 2003. 